\title{
Save of Environment and living organisms with weak energy of the water
}

\author{
Sunao Sugihara ${ }^{{ }^{*}}$, Hiroshi Maiwa ${ }^{2}$ and Kunihiko Hatanaka ${ }^{3}$ \\ ${ }^{1}$ Shonan Institute of Technology, Fugisawa, Japan. (General Inco. Assoc. Green Earth Again, SIGN water research Lab. Yokohama) \\ ${ }^{2}$ Shonan Institute of Technology, Fugisawa, Japan
}

${ }^{3}$ MCM Co. Ltd, Osaka, Japan

*Corresponding Author: Sunao Sugihara, Shonan Institute of Technology, Fugisawa, Japan. (General Inco. Assoc. Green Earth Again, SIGN water research Lab. Yokohama).

Received: September 04, 2021; Published: October 01, 2021

\begin{abstract}
It is well known that water can't be lack of plants as well as human body and water is 70\% occupies the oceans on the earth. There is little basic research for water although many a study has been reported for a macroscopic viewpoint of water, $\mathrm{H}_{2} \mathrm{O}$ molecule itself, such as a solvent. Furthermore, water must be essential to agriculture including soil and bacteria in it. The research of agriculture has not focused on the water, although they pay much attention to soil, a fertilizer and efficient harvest. Here we report the water a more than unusual which is completely different from our daily life water. Here, we present the small size water like an elementary particle that can be fabricated with higher pressure of more than $100 \mathrm{MPa}$. We indirectly confirmed the smallness of it with H-NMR and FTIR methods. As the result, the water can be easily absorbed into a living organism including a human body due to its size leading to the growth and respiration of a plant. Furthermore, we report that the water can function to change the nucleus resulting in the radioactive reduction.
\end{abstract}

Keywords: Small size of water; 100MPa; Better absorption; Water information; Radiation reduction

\section{Introduction}

Generally speaking, sunlight is essential to a plant as well known and at the same time, the explanation of how light affects some seeds and causes them to be in a state of readiness for germination and yet prevents other seeds from germinating if necessary is highly complex. It is mainly the light's effect upon a plant pigment called phytochrome within the seed. Photoblastic [1] describes a seed whose germination is influenced by light such as lettuce, and woodland strawberry (Fragaria) and mistletoe (Yadorigi) [2]. The plant pigment relates to the type of light which the seed receives. As a generalization, light in the red wavelength usually promotes germination, whereas blue light inhibits it. Phytochrome plays the role of signal transduction in the receptor. The factors are light, temperature and water. The light spreads from ultraviolet rays (wavelength of $200 \sim 380 \mathrm{~nm}$ ) through far-infrared (wavelength of 10 20 $\mu \mathrm{m}$ ) [1]. And temperature ranges are $288 \sim 303 \mathrm{~K}$ ). Considering temperature, the zone of a rice-growth in Japan becomes towards Hokkaido in the northern part because of global warming. Furthermore, there are some areas of lack of water on the earth always and sometimes drought and people draw underground water leading to the depletion. Therefore, we must devise how we effectively give water to a plant so that a plant can easily absorb water. Light and water are two essential items. Here, we present the SIGN water (Spin Information Gauge Network) which can effectively provide light and elementary particle-like small water to a plant emitting far infrared beam through terahertz wave. More than these phenomena relating to chemical reductive function, radiation reduction in Fukushima contaminated soils cover another meaning of nuclear reaction with the SIGN water. Now the SIGN water involves the presumed particle, infoton $\left\langle\mathrm{H}^{+} \sim \mathrm{e}^{-}\right\rangle$[3] which is neither hydrogen atom nor proton and electron, and they exist stably for a long time period transferring its information. We discuss the mechanisms of chemical reduction and decrease of radioactivity as well.

Citation: Sunao Sugihara., et al. "Save of Environment and living organisms with weak energy of the water". Medicon Agriculture \& Environmental Sciences 1.2 (2021): 02-09. 


\section{Materials \& Methods}

We can fabricate SIGN water under high pressure to tap water more than $100 \mathrm{MPa}$ [4] without any additive, which involves the pico-size particle such as infoton, $\left\langle\mathrm{H}^{+} \sim \mathrm{e}^{-}>\right.$and transfers to another substances as information associating with the momentum. These substances are air (we can especially activate nitrogen rather than oxygen because of the 2p [3] electron of outermost), plastics, ceramics, glass, a metal and other water. We use "activation or activated "as the terminology relating to use SIGN water information. Furthermore, we must indirectly evaluate a smallness of water when compare the spectra of H-NMR (R-90, Hitachi Co. Ltd) and FTIR (6000, JASCO) with those of control water. We use the scanning electron microscope of JEOL to look at the coffee powder. The methods of information transferring are immersed into SIGN water, contacting to the activated substance in direct and keeping the captioned material at a several distance like 100 to $200 \mathrm{~mm}$. Oxygen analysis in a polyethylene bag is performed using FERRER F16P5 gas analyzer. Furthermore, radiation measurement is used Geiger-Müller counter which can detect total $(\alpha+\beta+\gamma)$ and $(\beta+\gamma)$, separately. We can use Radiation Alert Inspector EXP as well.

\section{Results and Discussion}

Permeability of SIGN water due to smallness

We estimate the size of infoton in SIGN water corresponding to the size of hydrogen atom and of $\mathrm{H}^{+}$[4-6]. We activate the salad oil bottle transferring infoton's information by immersing into SIGN water so that we can experience the smallness of the activated oil as shown in Fig.1. A few drops of activated oil are put on the newspaper and after fifteen minutes, they penetrate onto the $6^{\text {th }}$ pages while the normal oil stops on the $3^{\text {rd }}$ page.
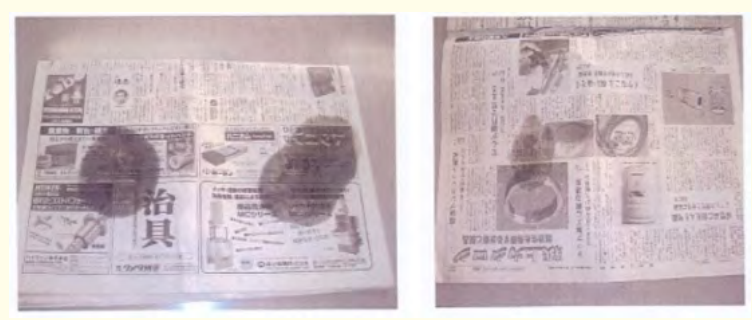

Figure 1: Permeability test; Salad oils on the $6^{\text {th }}$ pages of a newspaper. Left: SIGN salad oil. Right: Normal.

The photographs in Fig.2 show the coffee powder, and one of which is the normal powder and the other is activated. The surfaces describe the larger area of the powder in both multiplications. The lower photos of the activated coffee powder seem to tell the smaller particles. We assume that the activated air $\left(\mathrm{N}_{2}{ }^{*}\right.$ in particular) easily comes into the mass of powder. This mechanism is similarly the penetration of the oil into the layered newspaper. Namely, the infoton comes around the larger oil molecule resulting in smaller. 

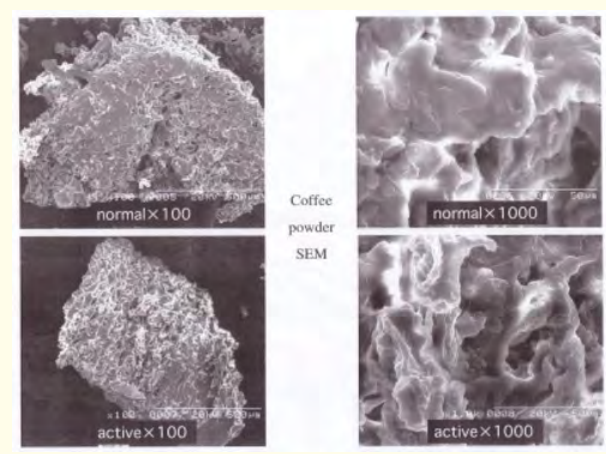

Figure 2: Upper two photos show normal coffee podwer. Lower two show SIGN treated powder indicating much smaller particles. Left: X100 and Right: X 1000.

Most people say "activated coffee" is mild and tasty as well as activated meat is tender.

Another evidence is ice in the beaker in which activated one does not show any cracks on it, meanwhile, the normal one indicates the cracks on both sides and the bottom. That means that water usually becomes volume expansion when it freezing. However, water liquid does not expand due to no volume change when air easily go away from the water with a smaller particle of SIGN water (activated water in Photo).
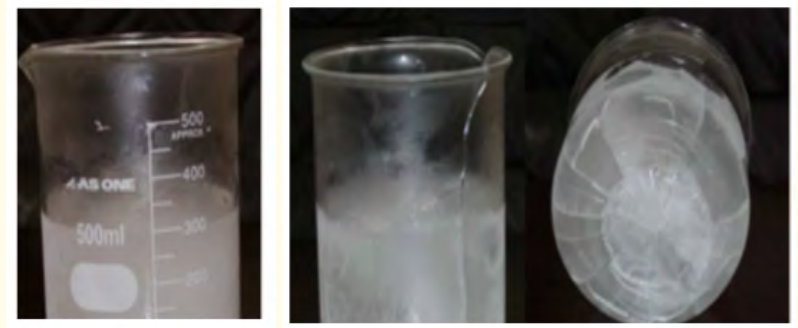

Figure 3: Estimation of water particle; Left: Active water, Right: Normal water.

For the explanation of a smallness, Fig. 3-1 depicts aquaporin protein to pass water only where the narrowest part of the protein is 140 picometer (1.4 Å) [7] so that SIGN water goes easily through it. Aquaporin protein is regarded to transmit only water [8]. Meanwhile, it seems to be difficult for the usual water, $n\left(\mathrm{H}_{2} \mathrm{O}\right)$ of $2.1 \AA$ approximately, which can be estimated from the references of Pauling [9] and Fröhlich [10]. 


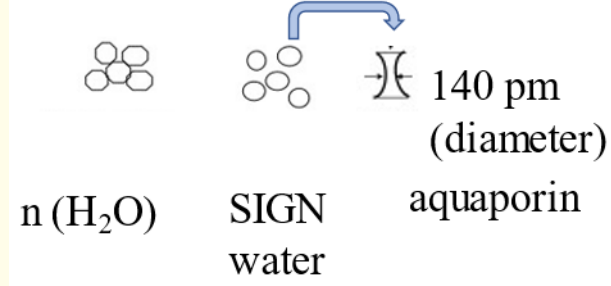

Figure 3-1: Aquaporin Protein to pass through water only for every living organism.

Now we can see the germination of white radish sprout to compare SIGN water with normal in five days after sowing in Fig. 4, where they are remarkably different.

Besides it, Fig. 5 depicts the root-growth of onion for 5 days in a dark box, and the number of roots is five in SIGN water box meanwhile, the normal one shows only one root.

These results indicate better absorption of water from roots and trunk because of the smaller particle in SIGN water as well.

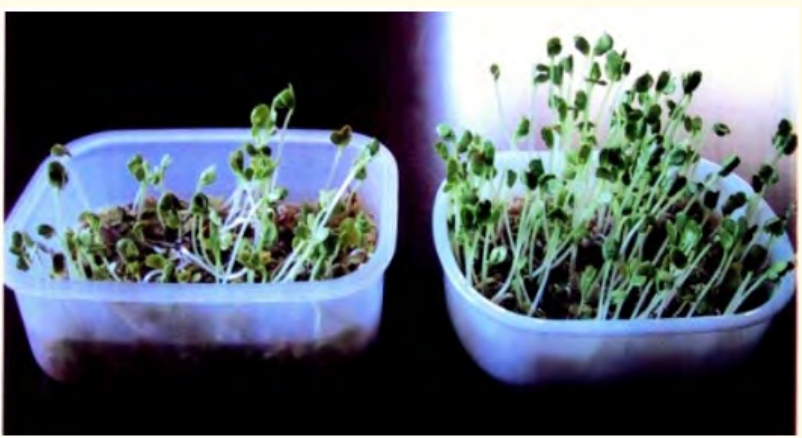

Figure 4: White radish sprout, Left: Normal, Right: active. Five days after sowing.

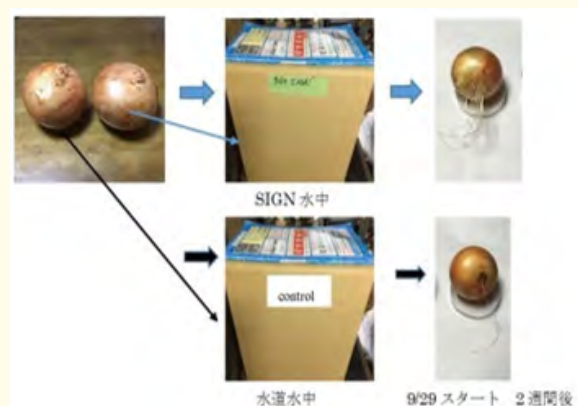

Figure 5: Root-growth of onions, Top: Active box, Down; Normal box. Both are kept in boxes for two weeks without light. 


\section{Generation of oxygen and anti-oxidation in activated bag and glass bottle}

A polyethylene bag can be activated by SIGN water to keep the vegetables inside fresh compare with control bags as shown in Fig. 6 . We reported the oxygen generation from mushrooms [11] as well.

Part of the mechanism is that the activated nitrogen avoid oxidization due to infoton from the activated poly bag. We depict it such as $\mathrm{N}_{2}{ }^{*}$ activated with $\left\langle\mathrm{H}^{+} \sim \mathrm{e}^{-}>\right.$.

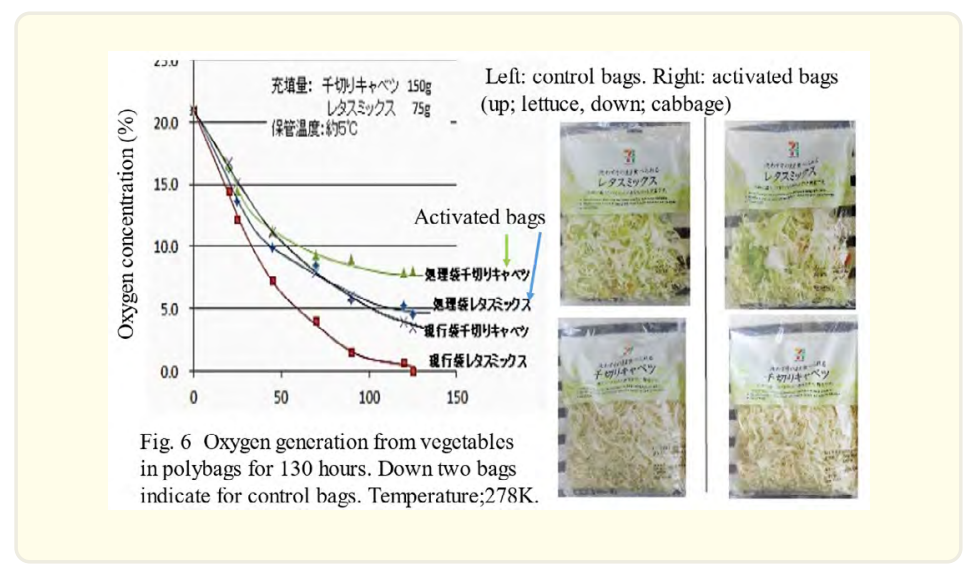

Furthermore, noticeable photos show the difference between fragrant, orange-colored leaves in an activated bottle and a normal one as shown in Fig. 7.

As a result, we can elucidate what happens in the sealed glass bottles; namely, the infoton information from the activated bottle forms nitrogen $\mathrm{N}_{2}{ }^{*}$ in the bottle and on the leaves as well as the case of Fig.6, then protects oxidation leading to a chemical reduction atmosphere. Oxygen does not function oxidation of leaves finally.

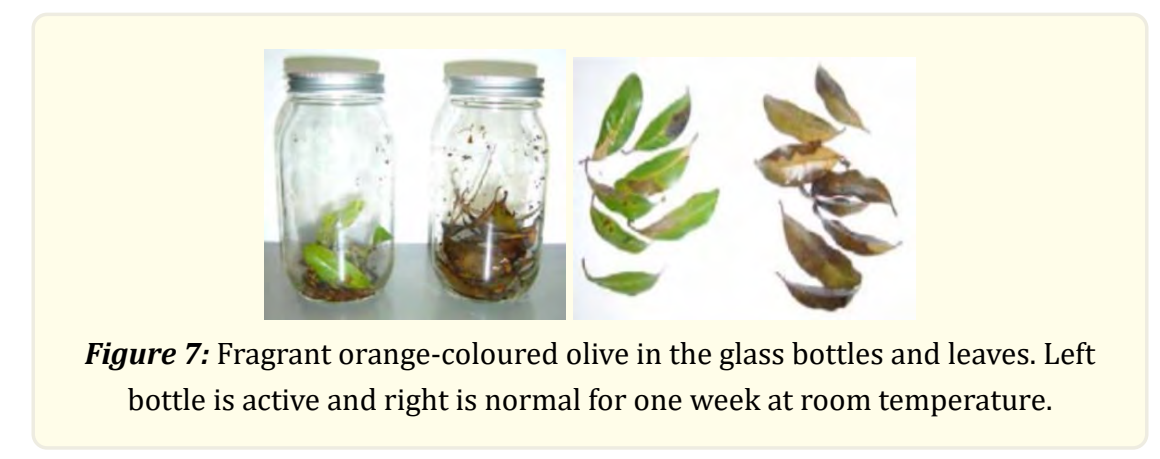

\section{Radiation reduction of mushrooms and in the rice field}

We have reported much data on radiation reduction of cesium134 and cesium137 in Fukushima since 2011, as shown in References. Here we choose agricultural firms of mushrooms and rice.

The SIGN treatment for 24 days reduces $47.5 \%$ in total as shown in Table 1 . And we show the data of radiation reduction in the mushrooms at a different place in Table 2. 


\begin{tabular}{|c|c|c|}
\hline $\begin{array}{c}\text { Radioactive } \\
\text { material }\end{array}$ & $\begin{array}{c}\text { Before SIGN } \\
\text { treatment }\end{array}$ & $\begin{array}{c}\text { After SIGN } \\
\text { treatment }\end{array}$ \\
\hline Cs134 & 832 & 422 \\
\hline Cs137 & 2046 & 1070 \\
\hline Total & $2878 \mathrm{~Bq} / \mathrm{kg}$ & 1512 \\
\hline
\end{tabular}

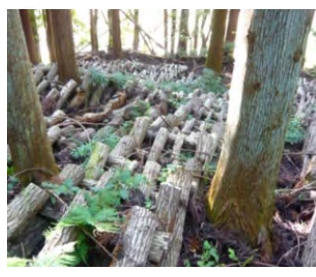

Table 1: Radiation reduction of mushroom (2013/4 in the mountain side)

\begin{tabular}{|c|c|c|}
\hline $\begin{array}{c}\text { Radioactive ma- } \\
\text { terial }\end{array}$ & $\begin{array}{c}\text { Before SIGN treat- } \\
\text { ment }\end{array}$ & $\begin{array}{c}\text { After SIGN } \\
\text { treatment }\end{array}$ \\
\hline Cs134 & 37 & No detectable \\
\hline Cs137 & 74 & No detectable \\
\hline Total & $111 \mathrm{~Bq} / \mathrm{kg}$ & $-\cdots----$ \\
\hline
\end{tabular}

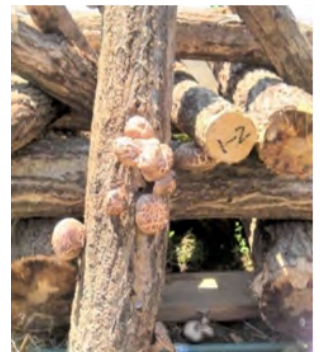

Table 2: Radiation reduction of mushroom (2014/4 at farm).

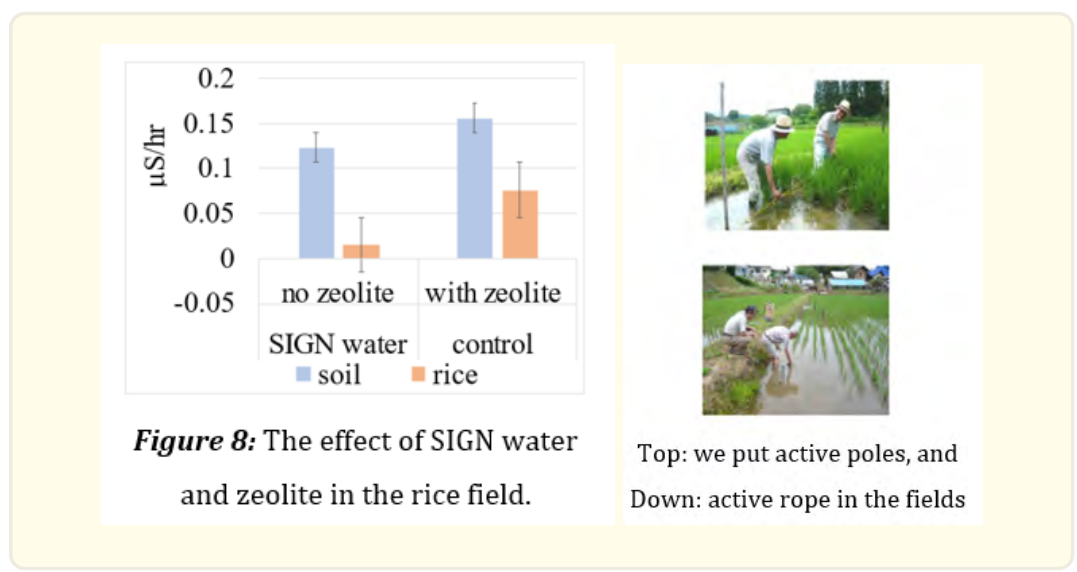

The farmer gave us one rice field without zeolite fortunately and we tried this field to activate with the activated rope. Fig.8 depicts the comparison of radioactivity between SIGN treatment, and control with zeolite additive (aluminosilicate involving $\mathrm{Na}^{+}$) in rice field (sizes $30 \mathrm{~m} \times 20 \mathrm{~m}$ ). Cesium oxide and its hydroxide are approximately twice larger than Cs oxides, so they just adsorb on the zeolite surface as they are in the state of radioactive material in the rice field. For SIGN water, we performed the active four ropes (30m) resulting in the graph (we tried 25 active poles) as well. Here is why radioactivity reduces is change of cesium to the stable element of barium [4]. We discuss the mechanism in the next section.

\section{Mechanisms of radiation reduction}

The cesium spontaneously changes under $\beta$ disintegration in 2.065 and 30.3 years for Cs134 and Cs137 of a half-life, respectively, and we proposed the theoretical formula to reduce a half-life of radioactivity [11]. 
The mechanism of nuclear reaction is following which is one of $\beta$ disintegration, namely, neutron changes to proton, electron and anti-neutrino [6].

$$
\mathrm{n} \rightarrow \mathrm{p}+e^{-}+\bar{v}
$$

Now, infoton react to caesium 137 (and caesium 134) when infoton obtains kinetic energy from caesium's radiation [12, 13]; the symbol, $\approx \mathrm{n}$ means that the weight of infoton closes to neutron by the difference of $0.013 \%$.

$$
\begin{aligned}
& { }_{55}^{137} \mathrm{Cs}+<\mathrm{H}^{+} \sim \mathrm{e}^{-}>(\approx \mathrm{n}) \rightarrow{ }_{56}^{138} \mathrm{Ba}+\mathrm{e}^{-}+\bar{v} \\
& { }_{55}^{134} C s+\left\langle\mathrm{H}^{+} \sim \mathrm{e}^{-}\right\rangle(\approx \mathrm{n}) \rightarrow{ }_{56}^{135} \mathrm{Ba}+\mathrm{e}^{-}+\bar{v}
\end{aligned}
$$

An interesting mechanism to reduced radioactivity seems to be due to mycelium, that is the vegetative part of a fungus-like bacterial colony (thread-like hyphae).

This mechanism is similar to that the microbes could cope in underground radioactive waste disposal sites, and we also found purple non-sulfur bacteria could change the radioactive elements to stable barium in the contaminated weeds in Fukushima [14, 15].

\section{Conclusion}

We discussed the macroscopic phenomena and nuclear reaction when the water (SIGN water) becomes smaller like pico-size. These characteristics are better absorption, easier transfer of its information to other substances involving an air (depicted as $\mathrm{N}_{2}{ }^{*}$ activated with $<\mathrm{H}^{+} \sim \mathrm{e}^{-}>$), and oxygen generation.

Furthermore, we found in Fukushima that radioactivity reduced by the reaction of cesium with infoton, $<\mathrm{H}^{+} \sim \mathrm{e}^{-}>$relating to the formation of the stable element such as barium and proposed its mechanism. We carry out to reduce tritium in Fukushima based on these achievements.

\section{Acknowledgement}

We express the thankfulness for helpful sampling and study to Messrs. Y. Nagasaka, N. Iwamoto and for providing the working space to Mr. G. Satoh in Fukushima.

\section{References}

1. https://ja.wikipedia.org/wiki/

2. https://ja.wikipedia.org/wiki/Yadorigi

3. Sugihara S. Infoton: Certificate of trademark registration No. 5138668, Japan Patent Office (2008).

4. Sugihara S. "Deactivation of Radiation from Radioactive Materials Contaminated in a Nuclear Power Plant Accident". Water 5 (2013): 69-85.

5. Emsley J. "The Elements". 3rd ed., Oxford: Clarendon Press (1998).

6. Fermi E. "Nuclear Physics". (Revised edition), University of Chicago Press (1950).

7. Kozono D., et al. "Aquapolin water channels: atomic structure and molecular dyanamics, meet clinical medicine". J Clin Invest 109.11 (2002): 1395-1399.

8. Yasui M. "Molecular Mechanisms and Drug Development in Aquaporin water Channel Disease: Structure and Function of Aquaporins". J. Pharmacol. Sci 96.3 (2004): 260-263.

9. Pauling L. "The Nature of Chemical Bond". 3rd ed, George Banta Company Inc (1960).

10. Frölich H. The Theory of Dielectrics, 2nd Edition, Oxford at The Claredon Press, translated by T Nagamiya, Y Nagai, Yoshioka shoten (Kyoto) (1965). 
11. Sugihara S., et al. "The Mechanisms of Activation of Substances by Minimal Catalyst Water and Application in Keeping Foods Fresh". Water 3 (2011): 87-94.

12. Sugihara S. "Faster disintegration of radioactive substances using energy of specially-processed water and theoretical prediction of a half-life of radionuclide". International Journal of Current Research and Academic Review 3.8 (2015): 196-207.

13. Sugihara S. "Model for Transmutation of Elements using Weak Energy of Water Leading to Faster Disintegration of Radionuclides". Water 10 (2018): 82-98.

14. Sasaki K. et al. "Practical Removal of Radioactivity from Soils in Fukushima Using Immobilized Photosynthetic Bacteria Combined with Anaerobic Digestion and Lactic Acid Fermentation as Pre-Treatment”. Biosci Biotechnol Biochem 76.9 (2012): 1809-1814.

15. Sugihara S. and So Y. "Purple Non-Sulfur Bacteria Can Change the Radioactive Elements in the Contaminated Weeds to Stable One". EC Agriculture 5.3 (2019): 134-138.

Volume 1 Issue 2 October 2021

(C) All rights are reserved by Sunao Sugihara., et al. 